\title{
Imaging of hypoxia in mouse atherosclerotic plaques with ${ }^{64} \mathrm{Cu}$-ATSM
}

\author{
Xingyu Nie, B.S. ${ }^{1,3}$, Gwendalyn J. Randolph, Ph.D. ${ }^{2}$, Andrew Elvington, Ph.D. ${ }^{2}$, \\ Nilantha Bandara, Ph.D. ${ }^{1}$, Alexander Zheleznyak, B.A. ${ }^{1}$, Robert J. Gropler, M.D. ${ }^{1}$, \\ Pamela K. Woodard, M.D. ${ }^{1,3,4}$, Suzanne E. Lapi, Ph.D. ${ }^{1,2,3, *}$
}

${ }^{1}$ Mallinckrodt Institute of Radiology, Washington University School of Medicine, St. Louis, MO

${ }^{2}$ Division of Biology and Biomedical Sciences, Washington University in St. Louis

${ }^{3}$ Department of Biomedical Engineering, Washington University in St. Louis

${ }^{4}$ Diabetic Cardiovascular Disease Center, Washington University in St. Louis

*Corresponding author:

510 South Kingshighway, Campus Box 8225

Washington University School of Medicine

Mallinckrodt Institute of Radiology

St. Louis, MO 63110-1016

Tel: (314) 362-4696

Fax: (314)362-9940

lapis@mir.wustl.edu

Key words: Cu-ATSM, Hypoxia, Atherosclerosis, Apo E, copper-64

Abbreviated title: ${ }^{64} \mathrm{Cu}$-ATSM imaging of plaque hypoxia in mouse 
Introduction: Cardiovascular disease is the leading cause of death in the United States. The identification of vulnerable plaque at risk of rupture has been a major focus of research. Hypoxia has been identified as a potential factor in the formation of vulnerable plaque, and it is clear that decreased oxygen plays a role in the development of plaque angiogenesis leading to plaque destabilization. The purpose of this study is to demonstrate the feasibility of copper-64 labeled diacetyl-bis $\left(\mathrm{N}^{4}\right.$-methylthiosemicarbazone) $\left({ }^{64} \mathrm{Cu}\right.$-ATSM), a positron-emitting radiopharmaceutical taken up in low-oxygen-tension cells, for the identification of hypoxic and potentially unstable atherosclerotic plaque in a mouse model. could help facilitate the study of plaque biology in human patients.

Methods: ${ }^{64} \mathrm{Cu}$-ATSM PET was performed in 21 atherosclerotic apolipoprotein E knockout (ApoE ${ }^{-/}$) mice, 6 of which were fed high-fat diet (HFD) while the others received standard-chow diet (SCD), and 13 control wild type mice fed SCD. 4 SCD ApoE ${ }^{-/-}$mice and 4 SCD wild type mice also underwent ${ }^{18}$ F-fluorodeoxyglucose $\left({ }^{18} \mathrm{~F}-\mathrm{FDG}\right)$ positron emission tomography (PET) imaging one day prior to ${ }^{64} \mathrm{Cu}$-ATSM PET.

Results: ${ }^{64} \mathrm{Cu}$-ATSM uptake was increased in the aortic arch in SCD ApoE ${ }^{-/-}$mice (average aortic arch/muscle (A/M) standardized uptake value [1] ratio 7.5-30 minutes post injection: $(5.66 \pm 0.23)$ compared to control mice (A/M SUV ratio 7.5-30 minutes post injection $(3.87 \pm 0.22), p<0.0001)$. HFD ApoE ${ }^{-/-}$mice also showed similarly increased aortic arch uptake on PET imaging in comparison to control mice. Immunohistochemistry in both HFD and SCD ApoE ${ }^{-/-}$mice revealed noticeable hypoxia by pimonidazole stain in atherosclerosis which was co-localized to macrophage by CD68 staining. Autoradiography assessment demonstrated the presence of hypoxia by ${ }^{64} \mathrm{Cu}$-ATSM uptake correlated with pimonidazole uptake within the ex vivo atherosclerotic aortic arch specimens. A significant increase in ${ }^{18} \mathrm{~F}-\mathrm{FDG}$ uptake in the SCD $\mathrm{ApoE}^{-/-}$mice in comparison to controls was also observed at delayed time points.

Conclusion: This pre-clinical study suggests that ${ }^{64} \mathrm{Cu}-\mathrm{ATSM}$ is a potential PET tracer for hypoxia imaging in atherosclerosis.

\section{Advances in Knowledge and Implications for Patient Care:}

While studies in humans are necessary for conclusive data, in the long term, a ${ }^{64} \mathrm{Cu}$-ATSM PET imaging strategy 


\section{Introduction}

Cardiovascular atherosclerosis is the leading cause of death worldwide despite primary and secondary prevention. Cardiovascular disease impacts the public broadly and affects an estimated 80 million people in the United States [2]. Each year more than a million people in the United States experience a sudden cardiac event (acute coronary syndrome or sudden cardiac death) and an additional 700,000 experience stroke [3]. Diabetes mellitus, another leading cause of morbidity and mortality in Western nations, is strongly associated with accelerated atherosclerosis $-86 \%$ of patients with newly diagnosed diabetes have atherosclerosis and as blood glucose levels increase, the incidence of clinical or preclinical atherosclerosis also increases [4].

At present, there is a lack of an effective approach to monitor non-obstructive asymptomatic but potentially unstable atherosclerosis. Although ${ }^{18}$ F-Fluorodeoxyglucose $\left({ }^{18}\right.$ F-FDG) PET has been shown to detect vascular atheroma [5], it provides limited value for evaluating the coronary arteries due to the confounding effects of myocardial uptake of the radiotracer. Cu-ATSM was the first bis(thiosemicarbazone) complexes demonstrated to exhibit hypoxia selectivity [6-8], and has been extensively investigated for characterizing hypoxic tumors [9-14] in addition to a few studies addressing its potential application for imaging ischemic or hypoxic myocardium [1517]. If successful, copper-64 labeled diacetyl-bis $\left(\mathrm{N}^{4}\right.$-methylthiosemicarbazone) $\left({ }^{64} \mathrm{Cu}\right.$-ATSM) imaging would overcome this limitation.

In this study, we have assessed the feasibility of imaging the development of hypoxia in an apolipoprotein $\mathrm{E}$ knockout (ApoE $\mathrm{KO}$ or $\mathrm{ApoE}^{-1-}$ ) mouse model of atherosclerosis using the PET imaging agent ${ }^{64} \mathrm{Cu}-\mathrm{ATSM}$. Lack of ApoE results in severe hypercholesterolemia and spontaneously developed atherosclerotic lesions. Therefore, this mouse model is widely used to study atherosclerosis $[18,19]$. Using ${ }^{64} \mathrm{Cu}$-ATSM to target hypoxic cells within plaque is of interest to us because this imaging radiopharmaceutical has been used extensively in preclinical models and human subjects to assess tumor hypoxia in oncology but its use in cardiology has so far been limited to assessing myocardial ischemia $[8,16,17,20]$. However, there is growing evidence that the combination of increased oxygen demand together with impaired oxygen diffusion capacity also results in the presence of severe hypoxia ( $<1 \%$ oxygen) in macrophage-rich zones into the lesion [21-24]. Leppanen et al. [25] 3 
suggests that over time macrophages within the plaque core become ATP-depleted and severely hypoxic, contributing to their death and formation of a necrotic core that increases angiogenesis and plaque destabilization. The direct presence of hypoxia in the macrophage-rich center of human carotid atherosclerosis has been demonstrated by Sluimer et al. [23], and there is some preliminary data to suggest that hypoxia may be the cause for increased glucose utilization, and thus, increased ${ }^{18}$ F-FDG activity in atherosclerosis [26]. A recent study successfully assessed hypoxia in rabbit advanced atherosclerosis using ${ }^{18}$ F-fluoromisonidazole $\left({ }^{18}\right.$ F-FMISO) PET imaging [27]. Our study is to investigate the feasibility of ${ }^{64} \mathrm{Cu}-\mathrm{ATSM}$ for the identification of hypoxic and potentially unstable atherosclerotic plaque in a mouse model. In comparison to ${ }^{18} \mathrm{~F}-\mathrm{FMISO},{ }^{64} \mathrm{Cu}$-ATSM has two major advantages: higher cellular uptake and quicker washout from normoxic tissue [28]. The more efficient uptake and washout kinetics of ${ }^{64} \mathrm{Cu}-\mathrm{ATSM}$ in hypoxic and normoxic cells offers the possibility of a faster and more selective means of detecting hypoxia by PET imaging. Although different schemas in the retention mechanism of $\mathrm{Cu}$-ATSM were proposed in the literature, but, to date, there is a consensus that in vitro $\mathrm{Cu}$-ATSM undergoes bioreductive trapping under hypoxic conditions [8, 29-31]. As presented by Fujiyabashi et al. [8, 17], in theory $\mathrm{Cu}$-ATSM $\mathrm{Cu}(\mathrm{II})$ is a lipophilic molecule, with high membrane permeability and low redox potential, and is reduced only in hypoxic cells and involves electron transfer from hyper-reduced Complex I (ubiquinone oxidoreductase) using NADH as a two-electron donor. Upon the intracellular reduction, $\mathrm{Cu}-\mathrm{ATSM}$ becomes trapped irreversibly and thus the radioactivity accumulates in these areas. In normoxic cells, Complex I is incapable of reducing $\mathrm{Cu}$-ATSM. In addition, we will use the hypoxia-specific dye pimonidazole and the pan macrophage marker CD68 to assess for co-localization of hypoxia in macrophages. Pimonidazole is reduced in cells with low oxygen tension to form protein adducts that can be detected by immunostaining [32]. We hypothesized that there would be high PET image contrast between hypoxic and normoxic tissues after the administration of ${ }^{64} \mathrm{Cu}$-ATSM, and that the presence of hypoxia by ${ }^{64} \mathrm{Cu}$-ATSM uptake will correlate with pimonidazole uptake within the ex vivo atherosclerotic arch specimens. We also hypothesized that pimonidazole uptake would co-localize to macrophages (CD68) on immunohistochemistry.

\section{Materials and Methods}

\section{General}


All animal studies were performed under a protocol approved by the Animal Studies Committee at our

institution. Ten-month-old wild type $(\mathrm{C} 57 \mathrm{Bl} / 6, \mathrm{n}=7)$ mice weighting $\sim 30 \mathrm{~g}$ were purchased from Charles River Laboratories (Wilmington, MA) and fed standard-chow diet (SCD). One-year-old ApoE ${ }^{-/-}$mice $(n=9)$ spontaneously expressing atherosclerosis were fed SCD for one year and had roughly the same weight as the wild type mice prior to ${ }^{64} \mathrm{Cu}$-ATSM PET imaging. A subset of $\mathrm{ApoE}^{-/-}$mice $(\mathrm{n}=4)$ and wild type mice $(\mathrm{n}=4)$ also underwent ${ }^{18}$ F-FDG PET imaging in addition to ${ }^{64} \mathrm{Cu}$-ATSM PET imaging one day later. Additional SCD wild type mice $(n=6)$ and $\operatorname{ApoE}^{-/-}$mice fed either with $\operatorname{SCD}(n=6)$ or a high-fat Western type diet $(n=6$; HFD, containing $21.2 \%$ fat and $0.2 \%$ cholesterol; Harlan Laboratories, Inc., Indianapolis, IN) underwent longitudinal imaging. These mice underwent PET imaging in 2-month intervals for a total of 10 months. This was done in order to assess the uptake of ${ }^{64} \mathrm{Cu}$-ATSM at various stages of plaque development. The experimental arms are given below in Table 1. All chemicals, unless otherwise stated, were purchased from Sigma-Aldrich Chemical Co. (St. Louis, MO). Water was distilled and then deionized $\left(18 \mathrm{M} \Omega / \mathrm{cm}^{2}\right)$ by passing through a Milli-Q water filtration system (Millipore Corp., Milford, MA).

Copper-64 was prepared as previously described $[33,34]$. Radioactivity was counted with a Beckman Gamma 8000 counter containing a NaI crystal (Beckman Instruments, Inc., Irvine, CA). EM Science Silica Gel 60 F254 thick-layer chromatography $(\mathrm{TLC})$ plates $(10 \times 5 \mathrm{~cm})$ were purchased from EMD Millipore Corporation (Billerica, MA). Radio-TLC plates were analyzed using a BIOSCAN System 200 imaging scanner (Bioscan, Inc., Washington, DC).

Diacetyl-bis ( $\mathrm{N}^{4}$-methylthiosemicarbazonate) $\left[\mathrm{H}_{2}\right.$-ATSM] was labeled with ${ }^{64} \mathrm{Cu}$ using the methods developed in house. Briefly, $10 \mathrm{mg}$ of ATSM powder was dissolved in $1 \mathrm{ml}$ of DMSO to give an overall concentration of $10 \mathrm{mg} / \mathrm{mL}$. A total of $1 \mu \mathrm{L}(10 \mu \mathrm{g})$ of this solution was then added to $1 \mu \mathrm{L}(\sim 92.5 \mathrm{MBq})$ of ${ }^{64} \mathrm{CuCl}_{2}$ in $200 \mu \mathrm{l}$ of $1 \mathrm{M} \mathrm{NaOAc}$ or $3 \mathrm{M} \mathrm{HCl}$ buffer, at a concentration of $0.46 \mathrm{MBq} / \mu \mathrm{L}$. This solution was then stirred for 3 to 5 minutes and then allowed to sit briefly at room temperature, after which it was loaded onto a $\mathrm{C}_{18}$ Sep-Pak® Light (Waters Corporation, Milford, MA), which had been pre-conditioned with $5 \mathrm{~mL}$ of ethanol and 5 $\mathrm{mL}$ of water. After loading the sample, $10 \mathrm{~mL}$ of water was passed through to remove the DMSO and any unreacted ${ }^{64} \mathrm{Cu}$. The labeled complex was then eluted in $350 \mu \mathrm{L}$ of ethanol (following a $150 \mu \mathrm{L}$ ethanol elution for the void volume). The purity of the labeled material was determined by radio-TLC using silica gel plates with 
ethyl acetate as the mobile phase. Radiochemical yield was $75-85 \%$ and purity $>95 \%$.

\section{Dynamic Small Animal PET Imaging}

Small animal imaging studies were carried out on a Siemens Inveon (Siemens Medical Solutions USA, Inc., Malvern, PA) or Focus 220 microPET scanner (Concorde MicroSystem Inc., Knoxville, TN). Isoflurane (1-2\%) was used to induce and maintain anesthesia during imaging. Each animal received $\sim 3.7 \mathrm{MBq}$ of activity in $100 \mu \mathrm{L}$ saline via lateral tail-vein injection. Mice were imaged in pairs in a supine position in a specially designed bed. Imaging was performed using 0-30 minute dynamic scan sessions for ${ }^{64} \mathrm{Cu}-\mathrm{ATSM}$ or 0-60 minute dynamic scan sessions for ${ }^{18}$ F-FDG. PET data was reconstructed using standard methods with the maximum a posteriori probability (MAP) algorithm. ${ }^{64} \mathrm{Cu}$-ATSM images were reconstructed in 10 second intervals up to 2 minutes, 30 seconds intervals up to 5 minutes, and 5 minute intervals up to 30 minutes. ${ }^{18}$ F-FDG scans were reconstructed in 2-5 seconds intervals up to 1 minute p.i., 10-30 seconds intervals up to 4 minutes p.i., 60-120 second intervals up to 10 minutes p.i. and 5 minute intervals up 1 hour. CT was performed prior to each PET study for attenuation correction and anatomical co-localization of the PET data.

\section{Image Analysis}

Images were evaluated by measuring the radioactivity concentration of the aortic arch and non-target (thigh muscle) of each mouse on the co-registered PET/CT images using the Inveon Research Workplace (IRW; Siemens Medical Solutions USA, Inc., Malvern, PA).

Regions of interest (ROIs) were drawn around the entire aortic arch $\left(\sim 15 \mathrm{~mm}^{3}\right)$ or a region of $\sim 50 \mathrm{~mm}^{3}$ on the thigh muscle on multiple consecutive, transaxial image slices. Time activity curves (TACs) in $\mathrm{kBq} / \mathrm{cm}^{3}$ were generated by plotting the ROI values over time.

Standardized Uptake Values (SUVs) were calculated by dividing the decay-corrected activity per unit volume of tissue $\left(\mathrm{Bq} / \mathrm{cm}^{3}\right)$ by the injected activity per unit of body weight $(\mathrm{Bq} / \mathrm{g})$, as described by the following equation:

$$
\text { SUV }=\frac{\text { radioactivity concentration }\left(B q / \mathrm{cm}^{3}\right)}{\text { injected dose }(B q) / \text { body weight }(g)}
$$


The aortic arch-to-leg muscle (A/M) SUV ratios were calculated and compared.

\section{Statistical Methods}

Graph generation and statistical analysis were performed using GraphPad Prism version 6 (GraphPad Software Inc., La Jolla, CA). Differences between groups were evaluated by Student's $t$-test (two groups) or oneway ANOVA (three or more groups) using Fisher's least significant difference method for post-hoc test. Data were reported as mean \pm S.E.M. (standard error of mean) unless otherwise indicated and differences at the $95 \%$ confidence level $(P<0.05)$ were considered statistically significant.

\section{Immunohistochemistry}

4 mice from each subset (wild type, $\mathrm{ApoE}^{-/-}$fed $\mathrm{SCD}$ or $\mathrm{HDF}$ ) were sacrificed to collect ex-vivo endarterectomy specimens for histopathological assessment and pimonidazole immunohistochemistry. The animals were injected with the hypoxia-reactive reagent pimonidazole hydrochloride (Hypoxyprobe ${ }^{\mathrm{TM}}-1 \mathrm{Kit}^{\text {, }}$ Hypoxyprobe, Inc, Belmont, MA) 60-90 minutes before euthanasia. Specimens were embedded in paraffin and sectioned transversely. Serial $5 \mu \mathrm{m}$ sections of even intervals were placed on slides for immunohistochemistry and histology with hemotoxylin and eosin (H\&E) stains. Aortic arch specimens and leg muscle tissue specimens were stained for the presence of hypoxia using an antipimonidazole antibody (Natural Pharmacia Inc., Belmont, MA) and mounted in solution containing 4'-6-diamidino-2-phenylindole (Vector Laboratories, Palo Alto, CA). Although pimonidazole may react with reactive oxygen species [35], the antipimonidazole antibody only recognizes hypoxia derivatives [36].

Rat anti mouse CD68 antibody (AbD Serotec, Bio-Rad Laboratories, Hercules, CA) which recognizes mouse macrosialin for the identification of CD68 was used to stain atherosclerosis-associated macrophages [37-42] in the paraffin-embedded aortic arch of mouse, and the result was co-localized to the pimonidazole staining. Fluorescein isothiocyanate [43] and Cy3 fluorescent labeled antibodies were used as the secondary fluorescent antibodies, respectively. The slides were incubated with DAPI (4, 6-diamino-2-phenylindole) (Fluoro-Gel II with DAPI, electron microscopy sciences, Inc., Hatfield, MA) to show cell nuclei. Negative control staining was 
195

performed by replacing the primary antibody with matching isotype control followed by same fluorescent labeled secondary antibody. Immunohistochemistry slides were imaged by Leica TCS SP5 confocal laser scanning microscope (Leica Microsystems Inc., Buffalo Grove, IL).

\section{Autoradiography}

Specimens from $4 \mathrm{SCD} \mathrm{ApoE}^{-/-}$mice and 4 wild-type control mice were collected for autoradiography. The animals were injected with pimonidazole hydrochloride 60-90 minutes before euthanasia. Harvested fresh tissues of aortic arch (with heart attached) were fixed in 4\% Paraformaldehyde (PFA) for $\sim 12$ hours and cut transversely into a series of adjacent sections on a cryostat (Leica) at $20 \mu \mathrm{m}$ thickness and attached to adhesive glass slides (CFSA 1X, Leica Microystems, Buffalo Grove, IL). Both the aortic arch of the control mice and the heart of the same $\mathrm{ApoE}^{-/-}$mice were used as negative controls. The slides used for autoradiography were covered by adhesive tape (CryoJane Tape Transfer System ${ }^{\circledR}$, Leica Microsystems, GmbH, Nussloch, Germany) and exposed to a phosphor imaging plate (GE Healthcare Life Sciences, Pittsburgh, PA) for 12 hours at $-20^{\circ} \mathrm{C}$, and the plates were scanned using phosphor imager plate scanner (Storm ${ }^{\circledR} 840$, Amersham Biosciences Corp., Piscataway, NJ)). The resulting images were processed using ImageQuant 5.2 (Molecular Dynamics, Inc, Sunnyvale, CA) and ImageJ (v1.48, public domain) software. After decaying for at least 3 days, the adjacent slides were treated with pimonidazole and CD68 staining for the presence of hypoxia and macrophages. Due to the different resolution of the immunohistochemistry image obtained from the confocal microscopy $(<5 \mu \mathrm{m})$ and the autoradiograph obtained from the plate scanner $(50 \mu \mathrm{m})$, the autoradiograph were scaled up 11.2 times with bilinear interpolation to match the size of the immunohistochemistry images in the same ROI for comparison.

\section{Results}

${ }^{64} \mathrm{Cu}$-ATSM was distributed rapidly in the blood pool and quickly excreted; thus activity was found in the kidney and liver at all time-points post injection likely due to clearance. ROIs were drawn on the PET and CT coregistered images over the aortic arch and an area of leg muscle on each mouse after administration of ${ }^{64} \mathrm{Cu}-$ ATSM or ${ }^{18}$ F-FDG (Figure 1).

7.5 minutes post injection of ${ }^{64} \mathrm{Cu}$-ATSM, the radioactivity in the aortic arch and leg muscle was stable 8 
(Figure 2A), while the difference in time activity curves (TACs) of aortic arch between the SCD ApoE ${ }^{-/}$mice and control mice increased over time from 15 minutes post injection of ${ }^{18} \mathrm{~F}-\mathrm{FDG}$ until the end of imaging (Figure 2B). There was no significant difference in activity in leg muscle (background) (Figure 2, A and B). The average SUVs of the aortic arch 7.5-30 minutes post injection of ${ }^{64} \mathrm{Cu}$-ATSM were significantly higher in the SCD ApoE ${ }^{-/-}$mice $(\mathrm{n}=9)$ than the wild type mice $(\mathrm{n}=7): 7.80 \pm 0.41$ and $5.45 \pm 0.52$, respectively $(p=0.004)$, as were average aortic arch to muscle (A/M) SUV ratios of the $\mathrm{SCD} \mathrm{ApoE}^{-/-}$mice and the wild type mice: $5.66 \pm 0.23$ and $3.87 \pm$ 0.22 , respectively $(p<0.0001)$ (Figures $3 \mathrm{~A})$. For the mice injected with ${ }^{18}$ F-FDG, the A/M SUV ratios between $\mathrm{SCD} A \mathrm{ApE}^{-/-}$mice and control mice became statistically significant at about 40 minutes post injection of ${ }^{18} \mathrm{~F}-\mathrm{FDG}$ (Figure 3B). The 40-60 minutes p.i. average A/M SUV ratio difference between $\mathrm{SCD}_{\text {ApoE }}{ }^{--}$mice $(\mathrm{n}=4,8.07 \pm$ 0.96) and control mice $(\mathrm{n}=4,4.55 \pm 0.21)$ after ${ }^{18}$ F-FDG injection (Figure 4) was also significant $(p<0.005)$, as was the average A/M SUV ratio difference (5.57 \pm 0.38 V.S. $3.67 \pm 0.61) 7.5-30$ minutes after ${ }^{64} \mathrm{Cu}-\mathrm{ATSM}$ for the same subset of mice.

Immunohistochemistry of the aortic arch in $\mathrm{ApoE}^{-/-}$mice showed the presence of atherosclerosis whereas immunohistochemistry of the aortic arch of wild type mice did not. Pimonidazole uptake was found in the aortic arch of both SCD and HFD ApoE ${ }^{-/}$mice (Figure 5 and Supplemental Figure 1). There was large overlap of the fluorescent areas corresponding to the CD68 macrophage staining co-localized to the pimonidazole adducts, demonstrating co-localization of hypoxia to macrophages (Figure 5, Supplemental Figure 1). Wild type aortic specimens did not demonstrate hypoxia by pimonidazole staining (Supplemental Figure 2). The DAPI staining for nuclei delineated and confirmed the cellular components of the plaques imaged.

Autoradiographs from different transverse slides confirmed that SCD ApoE ${ }^{-/-}$mice had higher uptake of ${ }^{64} \mathrm{Cu}$-ATSM in comparison to the aortic arch of control mice as well as the heart of the same ApoE ${ }^{-/-}$mice (Figure 6A). The hot spots in the scaled-up autoradiograph (Figure 6B) regionally co-localized to the immunohistochemistry image of the adjacent slide (Figure 6, C-E).

The results of our longitudinal studies comparing ${ }^{64} \mathrm{Cu}$-ATSM uptake in SCD and HFD ApoE ${ }^{-/-}$mice at various time points suggest that both groups of mice developed hypoxic atherosclerosis longitudinally over time. There was no significant difference in A/M SUV ratios between the three groups of mice at 14 weeks old, suggesting that no advanced atherosclerosis had been developed in the $\mathrm{ApoE}^{-/-}$mice at that age. However, ${ }^{64} \mathrm{Cu}-$ 
ATSM uptake in the both SCD and HFD fed $\mathrm{ApoE}^{-/-}$mice increased significantly from 14 to 23 weeks $(p<0.05$, Figure 7) with both SCD and HFD ApoE ${ }^{-/-}$mice showing significantly higher A/M SUV ratios at 23 weeks $(p<$ 0.01) in comparison to the wild-type control mice fed with standard chow. The difference between SCD and HFD $\mathrm{ApoE}^{-/-}$mice progressively increased over time until 32 weeks old and began to decrease until end of the study (41 weeks old). Although HFD ApoE ${ }^{-/-}$mice always had higher A/M SUV ratios than the SCD ApoE ${ }^{-/-}$mice, this difference was only statistically significant at 32 weeks.

\section{Discussion}

The overall goal of the current study was to investigate the use of ${ }^{64} \mathrm{Cu}$-ATSM PET imaging for determination of hypoxia in atherosclerotic plaque. This strategy has the potential to aid physicians in stratifying patients into high and low risk populations. We have made significant strides in demonstrating that the hypoxic cell PET imaging agent ${ }^{64} \mathrm{Cu}$-ATSM can be used for the imaging of hypoxic plaque, and have collected preliminary data to support further study to fully validate the feasibility of imaging the extent of hypoxia in mouse models of atherosclerosis. We also conducted a longitudinal study investigating the role of diet and age in this model, and thus form the basis of our future preclinical and clinical studies.

${ }^{64} \mathrm{Cu}-\mathrm{ATSM}$ is currently an approved Food and Drug Administration Investigational New Drug, thus this agent is already in use in a Phase II multicenter trial of oncologic patients at our institution [44]. Retrospective review of 8 sequential PET-CT examinations in cervical cancer patients imaged with ${ }^{64} \mathrm{Cu}$-ATSM from their study revealed ${ }^{64} \mathrm{Cu}$-ATSM uptake was only present in regions that corresponded to atherosclerosis on CT in the iliac arteries of one diabetic patient who died from myocardial infarction [45]. These anecdotal findings raised the suggestion the ${ }^{64} \mathrm{Cu}$-ATSM is a more discriminating agent in identifying potentially unstable atherosclerotic lesions.

It is well established that macrophages play a key role in atherosclerosis [46]. In the initial stages of atherogenesis, modified lipoproteins recruit monocytes and $\mathrm{T}$ cells into macrophages and internalize the modified lipoproteins, resulting in the accumulation of highly oxygen-consuming lipid-loaded macrophages (foam cells) in developing lesions before apoptosis [47]. The present of plaque hypoxia in macrophage-rich areas with neovascularization has been demonstrated in rabbit advanced atherosclerosis [27]. Despite relatively low 10 
resolution for autoradioagraphy, the brightest area in the autoradiograph, which indicated the highest ${ }^{64} \mathrm{Cu}-\mathrm{ATSM}$ uptake, regionally correlated to the pimonidazole and CD68 positive areas, the elevated ${ }^{64} \mathrm{Cu}-\mathrm{ATSM}$ was accumulated in the hypoxic macrophage-rich core of the atherosclerotic plaques in the aortic arch of $\mathrm{ApoE}^{-1-}$ mouse. ${ }^{64} \mathrm{Cu}$-ATSM has time-dependent and cell-dependent spatial distribution and retention kinetics, which result in various correlation between the uptake of $\mathrm{Cu}$-ATSM and immunofluorescent markers of hypoxia in different tumor cell lines [48-53]. There are reports of mildly $\left(\mathrm{pO}_{2}<2 \% \mathrm{O}_{2}\right)$ [54] and severely hypoxic retention threshold (2.0-5.0 $\mathrm{mmHg}$ and even lower [55]; $0.5 \%$ and $0.1 \% \mathrm{O}_{2}$ [56]; versus $40-60 \mathrm{mmHg}$ in normal tissue [57]) of ${ }^{64} \mathrm{Cu}-$ ATSM in different tumor types and acquisition time after injection. In a recent review article by Colombié et al. [58], the authors attribute the low correlation between Cu-ATSM uptake and hypoxic distribution in some tumors to the differing redox status of them. These tumor types might have a lower than average redox potential with high concentrations of electron donors leading to reduction and trapping of Cu-ATSM in both hypoxic and normoxic areas, i.e. human prostate tumor which overexpresses the fatty acid synthase (FAS) because this enzyme requires a large amount reductive species (NADPH) as cofactor for function [58, 59]. In atherosclerosis, although the redox potential caused by ATP-consumption in the lipid-loaded macrophages does not tend to be unusually low, we are still uncertain about the exact oxygen retention threshold of ${ }^{64} \mathrm{Cu}$-ATSM in hypoxic plaque. It be either higher or lower than pimonidazole $\left(\mathrm{pO}_{2} \leq 10 \mathrm{~mm} \mathrm{Hg}\right)$, resulting in smaller or larger spatial distribution of ${ }^{64} \mathrm{Cu}$-ATSM than pimonidazole.

Although ${ }^{18}$ F-FDG has been a well-described agent for in vivo imaging of atherosclerosis in animal [42, 60] and human subjects [5] and there is strong experimental and clinical evidence supporting that the increased ${ }^{18} \mathrm{~F}-\mathrm{FDG}$ uptake in atherosclerotic plaque is associated with the abundance of macrophages, it is a relatively nonspecific tracer with many practical limitations [61] because it provides complementary information on metabolic function as opposed to hypoxia. ${ }^{18} \mathrm{~F}$-FDG vascular uptake can also present in vascular smooth muscle cells and endothelial cells [26, 62]. Moreover, because of the long time course of ${ }^{18}$ F-FDG in arteries, a longer ${ }^{18}$ F-FDG circulation time is always required for vascular ${ }^{18} \mathrm{~F}-\mathrm{FDG}$ PET imaging protocol, preferably at least 90 minutes [63]. One other hand, the rapid blood pool clearance of ${ }^{64} \mathrm{Cu}$-ATSM allowed PET imaging within 30 min of tracer injection, a significant advance over ${ }^{18}$ F-FDG. Our finding that the SUV and A/M SUV ratios between HFD and SCD ApoE ${ }^{-/-}$with ${ }^{64} \mathrm{Cu}$-ATSM imaging differ from a previous study using ${ }^{18} \mathrm{~F}-\mathrm{FDG}$ as the PET imaging agent 
where $\mathrm{ApoE}^{-{ }^{-}}$mice receiving SCD had stable and low ${ }^{18} \mathrm{~F}$-FDG SUVs while the $\mathrm{ApoE}^{-/-}$mice receiving HFD showed progressively higher ${ }^{18} \mathrm{~F}-\mathrm{FDG}$ uptake up to the end of their study at 32 weeks [42]. This difference may be secondary to the different retention mechanisms between ${ }^{64} \mathrm{Cu}$-ATSM and ${ }^{18} \mathrm{~F}$-FDG. It implies that the either the oxygen tension $\left(<1 \%\right.$ oxygen [64]) is too low to be distinguished by ${ }^{64} \mathrm{Cu}-\mathrm{ATSM}$ imaging or alternatively, this finding may also suggest that the relative effect of the $\mathrm{ApoE}^{-/-}$mouse model genetics is stronger than the effect of diet on hypoxia progression in atherosclerotic plaque, or even both reasons takes effects together.

Further studies could be performed using logistic regression analysis to compare immunoreactivity scores of pimonidazole-determined hypoxia in the plaques as well as other immunohistochemistry markers of hypoxia (HIF $1 \alpha$, HIF $2 \alpha$ and VEGF) to the continuous variable of SUV, and to the A/M SUV ratios post injection of ${ }^{64} \mathrm{Cu}-$ ATSM. HIF- $1 \alpha$ and HIF-2 $\alpha$ are often used as markers of hypoxia. The expression of VEGF is low in normal vessel wall and up-regulated by hypoxia, inflammatory mediators, and certain growth factors. The human study from Slumer et al. in 2008 [23] demonstrated increasing expression of these hypoxia markers over the development of atherosclerosis. Nevertheless, another study using an atherosclerotic murine model found that all three markers of hypoxia correlated negatively with $\mathrm{SUV}_{\text {mean }}$ of ${ }^{18} \mathrm{~F}-\mathrm{FDG}$ [42]. The discordant finding was explained by the limited number of lesions investigated in the human study, smaller lesions in mice compared to human, and potentially dissimilar gene expression of molecular markers of hypoxia between and mice and human, etc. In future studies, we will validate whether these hypoxia markers will correlate positively with the uptake of ${ }^{64} \mathrm{Cu}-\mathrm{ATSM}$ to provide more data to explain this discrepancy.

One limitation in the study is the relatively poor spatial resolution of the small animal PET and coregistered CT scanner. The diameter of mouse aortic arch is about $1 \mathrm{~mm}$ [65], which is at the same level of the microPET resolution (1-2 mm). As a result the effect of partial volume and spillover may deteriorate the imaging quality and cause underestimation the resultant radioactivity. In further studies we will increase the size of animal model from mouse to rabbit, and apply post-processing techniques to correct for partial volume effects. The tiny size of the mouse aortic arch, which may easily generate shift and deformation during obtaining adjacent sections for autoradiography and immunohistochemistry, together with the dramatic different resolution of the autoradiography plate scanner $(50 \mathrm{um})$ and the confocal microscope $(<5 \mathrm{um})$, brings up technical 
difficulty to correlate the autoradiograph and immunohistochemistry images in pixel level.

In order to justify the activity in the thigh muscle as the background activity for uptake normalization purposes, we collected the samples of aortic arch (with heart attached), blood pool and leg muscle from at least three SCD ApoE ${ }^{-/-}$mice and control mice after sacrificing (30 minute post injection of $\left.{ }^{64} \mathrm{Cu}-\mathrm{ATSM}\right)$. For the $\mathrm{ApoE}^{-/-}$mice, the \%ID/gram of aortic arch with heart (4.02 \pm 0.69$)$ was 1.5 time higher than that of blood $(2.72 \pm$ $0.18)$, and 5.1 times higher than that of muscle $(0.79 \pm 0.11)$. However, for the control mice the \%ID/gram of aortic arch with heart $(2.34 \pm 0.56)$ showed a similar value with blood $(2.30 \pm 0.60)$, and was 3.9 times higher than the muscle $(0.61 \pm 0.12)$. These findings suggest that activity of tracer in muscle is the same between the groups.

\section{Conclusion}

This study demonstrates the utility of ${ }^{64} \mathrm{Cu}$-ATSM for imaging hypoxia in atherosclerotic plaque, permitting image contrast between hypoxic and normoxic tissues 7.5-30 minutes post injection. ${ }^{64} \mathrm{Cu}$-ATSM imaging may assist in evaluating the progression of hypoxia over time in an $\mathrm{ApoE}^{-{ }_{-}}$mouse model.

\section{Acknowledgements}

The authors would like to thank the Washington University Isotope Production team for production of

${ }^{64} \mathrm{Cu}$, the pre-clinical imaging facility for animal PET imaging, Lisa Detering for animal surgery, and Jinbin Xu for the help in tissue sectioning

This research was supported in part by NIH grant 20110169, Department of Energy grant DESC0002032, and the Diabetic Cardiovascular Disease Center, Washington University, St. Louis.

The studies presented in this work were conducted in the MIR Pre-Clinical PET-CT Facility of the Washington University School of Medicine. This work was performed with the support from the Siteman Cancer Center Small Animal Imaging Core. 


\section{References}

[1] Hartmann DL, Wallace JM, Limpasuvan V, Thompson DW, and Holton JR. Can ozone depletion and global warming interact to produce rapid climate change? Proceedings of the National Academy of Sciences of the United States of America 2000;97:1412-7.

[2] Broderick J, Brott T, Kothari R, Miller R, Khoury J, Pancioli A, et al. The Greater Cincinnati/Northern Kentucky Stroke Study: preliminary first-ever and total incidence rates of stroke among blacks. Stroke 1998;29:415-21.

[3] Barzilay JI, Spiekerman CF, Kuller LH, Burke GL, Bittner V, Gottdiener JS, et al. Prevalence of clinical and isolated subclinical cardiovascular disease in older adults with glucose disorders - The Cardiovascular Health Study. Diabetes Care 2001;24:1233-9.

[4] Libby P and Zhao DX. Allograft arteriosclerosis and immune-driven angiogenesis. Circulation 2003;107:1237-9.

[5] Rudd JH, Myers KS, Bansilal S, Machac J, Rafique A, Farkouh M, et al. (18)Fluorodeoxyglucose positron emission tomography imaging of atherosclerotic plaque inflammation is highly reproducible: implications for atherosclerosis therapy trials. Journal of the American College of Cardiology 2007;50:892-6.

[6] Blower PJ, Lewis JS, and Zweit J. Copper radionuclides and radiopharmaceuticals in nuclear medicine. Nuclear medicine and biology 1996;23:957-80.

[7] Wada K, Fujibayashi Y, Tajima N, and Yokoyama A. CU-ATSM, an intracellular-accessible superoxide dismutase (SOD)-like copper complex: evaluation in an ischemia-reperfusion injury model. Biological \& pharmaceutical bulletin 1994;17:701-4.

[8] Fujibayashi Y, Taniuchi H, Yonekura Y, Ohtani H, Konishi J, and Yokoyama A. Copper-62-ATSM: a new hypoxia imaging agent with high membrane permeability and low redox potential. Journal of nuclear medicine : official publication, Society of Nuclear Medicine 1997;38:1155-60.

[9] Dehdashti F, Mintun MA, Lewis JS, Bradley J, Govindan R, Laforest R, et al. In vivo assessment of tumor hypoxia in lung cancer with 60Cu-ATSM. European journal of nuclear medicine and molecular imaging 2003;30:844-50.

[10] Takahashi N, Fujibayashi Y, Yonekura Y, Welch MJ, Waki A, Tsuchida T, et al. Evaluation of 62Cu labeled diacetyl-bis(N4methylthiosemicarbazone) as a hypoxic tissue tracer in patients with lung cancer. Annals of nuclear medicine 2000;14:323-8. [11] Dehdashti F, Grigsby PW, Lewis JS, Laforest R, Siegel BA, and Welch MJ. Assessing tumor hypoxia in cervical cancer by PET with 60Cu-labeled diacetyl-bis(N4-methylthiosemicarbazone). Journal of nuclear medicine : official publication, Society of Nuclear Medicine 2008;49:201-5.

[12] Dehdashti F, Grigsby PW, Mintun MA, Lewis JS, Siegel BA, and Welch MJ. Assessing tumor hypoxia in cervical cancer by positron emission tomography with 60CU-ATSM: relationship to therapeutic response-a preliminary report. International journal of radiation oncology, biology, physics 2003;55:1233-8.

[13] Lewis JS, Laforest R, Dehdashti F, Grigsby PW, Welch MJ, and Siegel BA. An imaging comparison of 64Cu-ATSM and 60Cu-ATSM in cancer of the uterine cervix. Journal of nuclear medicine : official publication, Society of Nuclear Medicine 2008;49:1177-82.

[14] Dietz DW, Dehdashti F, Grigsby PW, Malyapa RS, Myerson RJ, Picus J, et al. Tumor hypoxia detected by positron emission tomography with 60Cu-ATSM as a predictor of response and survival in patients undergoing Neoadjuvant chemoradiotherapy for rectal carcinoma: a pilot study. Diseases of the colon and rectum 2008;51:1641-8.

[15] Lewis JS, Herrero P, Sharp TL, Engelbach JA, Fujibayashi Y, Laforest R, et al. Delineation of hypoxia in canine myocardium using PET and copper(II)-diacetyl-bis(N(4)-methylthiosemicarbazone). Journal of nuclear medicine : official publication, Society of Nuclear Medicine 2002;43:1557-69.

[16] Takahashi N, Fujibayashi Y, Yonekura Y, Welch MJ, Waki A, Tsuchida T, et al. Copper-62 ATSM as a hypoxic tissue tracer in myocardial ischemia. Annals of nuclear medicine 2001;15:293-6.

[17] Fujibayashi Y, Cutler CS, Anderson CJ, McCarthy DW, Jones LA, Sharp T, et al. Comparative studies of Cu-64-ATSM and C11-acetate in an acute myocardial infarction model: ex vivo imaging of hypoxia in rats. Nuclear medicine and biology 1999;26:117-21.

[18] Khallou-Laschet J, Varthaman A, Fornasa G, Compain C, Gaston AT, Clement M, et al. Macrophage plasticity in experimental atherosclerosis. PloS one 2010;5:e8852.

[19] Zhang SH, Reddick RL, Piedrahita JA, and Maeda N. Spontaneous hypercholesterolemia and arterial lesions in mice lacking apolipoprotein E. Science 1992;258:468-71.

[20] Hoffman JM, Rasey JS, Spence AM, Shaw DW, and Krohn KA. Binding of the hypoxia tracer [3H]misonidazole in cerebral ischemia. Stroke 1987;18:168-76.

[21] Hulten LM and Levin M. The role of hypoxia in atherosclerosis. Curr Opin Lipidol 2009;20:409-14.

[22] Bjornheden $T$, Levin $M$, Evaldsson $M$, and Wiklund O. Evidence of hypoxic areas within the arterial wall in vivo. Arteriosclerosis, thrombosis, and vascular biology 1999;19:870-6.

[23] Sluimer JC, Gasc JM, van Wanroij JL, Kisters N, Groeneweg M, Sollewijn Gelpke MD, et al. Hypoxia, hypoxia-inducible 
transcription factor, and macrophages in human atherosclerotic plaques are correlated with intraplaque angiogenesis. Journal of the American College of Cardiology 2008;51:1258-65.

[24] Hueper WC. Arteriosclerosis. Arch Pathol 1944;38:0350-64.

[25] Leppanen O, Bjornheden T, Evaldsson M, Boren J, Wiklund O, and Levin M. ATP depletion in macrophages in the core of advanced rabbit atherosclerotic plaques in vivo. Atherosclerosis 2006;188:323-30.

[26] Folco EJ, Sheikine Y, Rocha VZ, Christen T, Shvartz E, Sukhova GK, et al. Hypoxia but not inflammation augments glucose uptake in human macrophages: Implications for imaging atherosclerosis with 18fluorine-labeled 2-deoxy-D-glucose positron emission tomography. Journal of the American College of Cardiology 2011;58:603-14.

[27] Mateo J, Izquierdo-Garcia D, Badimon JJ, Fayad ZA, and Fuster V. Noninvasive assessment of hypoxia in rabbit advanced atherosclerosis using (1)(8)F-fluoromisonidazole positron emission tomographic imaging. Circulation. Cardiovascular imaging 2014;7:312-20.

[28] Bourgeois M, Rajerison H, Guerard F, Mougin-Degraef M, Barbet J, Michel N, et al. Contribution of [64Cu]-ATSM PET in molecular imaging of tumour hypoxia compared to classical [18F]-MISO--a selected review. Nuclear medicine review. Central \& Eastern Europe 2011;14:90-5.

[29] Dearling JL, Lewis JS, Mullen GE, Welch MJ, and Blower PJ. Copper bis(thiosemicarbazone) complexes as hypoxia imaging agents: structure-activity relationships. Journal of biological inorganic chemistry : JBIC : a publication of the Society of Biological Inorganic Chemistry 2002;7:249-59.

[30] Burgman P, O'Donoghue JA, Lewis JS, Welch MJ, Humm JL, and Ling CC. Cell line-dependent differences in uptake and retention of the hypoxia-selective nuclear imaging agent Cu-ATSM. Nuclear medicine and biology 2005;32:623-30.

[31] Maurer RI, Blower PJ, Dilworth JR, Reynolds CA, Zheng Y, and Mullen GE. Studies on the mechanism of hypoxic selectivity in copper bis(thiosemicarbazone) radiopharmaceuticals. Journal of medicinal chemistry 2002;45:1420-31.

[32] Mayr M, Sidibe A, and Zampetaki A. The paradox of hypoxic and oxidative stress in atherosclerosis. Journal of the American College of Cardiology 2008;51:1266-7.

[33] McCarthy DW, Shefer RE, Klinkowstein RE, Bass LA, Margeneau WH, Cutler CS, et al. Efficient production of high specific activity 64Cu using a biomedical cyclotron. Nuclear medicine and biology 1997;24:35-43.

[34] Kume M, Carey PC, Gaehle G, Madrid E, Voller T, Margenau W, et al. A semi-automated system for the routine production of copper-64. Applied radiation and isotopes : including data, instrumentation and methods for use in agriculture, industry and medicine 2012;70:1803-6.

[35] Stary HC, Chandler AB, Dinsmore RE, Fuster V, Glagov S, Insull W, Jr., et al. A definition of advanced types of atherosclerotic lesions and a histological classification of atherosclerosis. A report from the Committee on Vascular Lesions of the Council on Arteriosclerosis, American Heart Association. Circulation 1995;92:1355-74.

[36] Fuster D, Magrina J, Ricart MJ, Pascual J, Laterza C, Setoain FJ, et al. Noninvasive assessment of cardiac risk in type I diabetic patients being evaluated for combined pancreas-kidney transplantation using dipyridamole-MIBI perfusion tomographic scintigraphy. Transplant international : official journal of the European Society for Organ Transplantation 2000;13:327-32.

[37] Duivenvoorden R, Tang J, Cormode DP, Mieszawska AJ, Izquierdo-Garcia D, Ozcan C, et al. A statin-loaded reconstituted high-density lipoprotein nanoparticle inhibits atherosclerotic plaque inflammation. Nature communications 2014;5:3065.

[38] Amirbekian V, Lipinski MJ, Briley-Saebo KC, Amirbekian S, Aguinaldo JG, Weinreb DB, et al. Detecting and assessing macrophages in vivo to evaluate atherosclerosis noninvasively using molecular MRI. Proceedings of the National Academy of Sciences of the United States of America 2007;104:961-6.

[39] Tacke F, Alvarez D, Kaplan TJ, Jakubzick C, Spanbroek R, Llodra J, et al. Monocyte subsets differentially employ CCR2, CCR5, and CX3CR1 to accumulate within atherosclerotic plaques. The Journal of clinical investigation 2007;117:185-94.

[40] Angheloiu GO, van de Poll SW, Georgakoudi I, Motz JT, Haka AS, Podrez E, et al. Intrinsic versus laser-induced fluorescence spectroscopy for coronary atherosclerosis: a generational comparison model for testing diagnostic accuracy. Applied spectroscopy 2012;66:1403-10.

[41] Potteaux S, Gautier EL, Hutchison SB, van Rooijen N, Rader DJ, Thomas MJ, et al. Suppressed monocyte recruitment drives macrophage removal from atherosclerotic plaques of Apoe-/- mice during disease regression. The Journal of clinical investigation 2011;121:2025-36.

[42] Hag AM, Pedersen SF, Christoffersen C, Binderup T, Jensen MM, Jorgensen JT, et al. (18)F-FDG PET imaging of murine atherosclerosis: association with gene expression of key molecular markers. PloS one 2012;7:e50908.

[43] Gray RE, Fitch M, Saunders PR, Wilkinson A, Ross CP, Franssen E, et al. Complementary health practitioners' attitudes, practices and knowledge related to women's cancers. Cancer prevention \& control : CPC = Prevention \& controle en cancerologie : PCC 1999;3:77-82.

[44] Dehdashti F, et al. Copper Cu 64-ATSM and PET/CT Scan in Predicting Disease Progression in Patients With NewlyDiagnosed Stage IB, Stage II, Stage III, or Stage IVA Cervical Cancer Who Are Undergoing Chemoradiotherapy Per NCCN 
Guidelines (ACRIN 6682). 2013.

[45] Woodard PKaD, F. Personal communication.; 2014.

[46] Smith JD, Trogan E, Ginsberg M, Grigaux C, Tian J, and Miyata M. Decreased atherosclerosis in mice deficient in both macrophage colony-stimulating factor (op) and apolipoprotein E. Proceedings of the National Academy of Sciences of the United States of America 1995;92:8264-8.

[47] Hulten LM and Levin M. The role of hypoxia in atherosclerosis. Current opinion in lipidology 2009;20:409-14.

[48] O'Donoghue JA, Zanzonico P, Pugachev A, Wen B, Smith-Jones P, Cai S, et al. Assessment of regional tumor hypoxia using 18F-fluoromisonidazole and $64 \mathrm{Cu}(\mathrm{II})$-diacetyl-bis(N4-methylthiosemicarbazone) positron emission tomography: Comparative study featuring microPET imaging, Po2 probe measurement, autoradiography, and fluorescent microscopy in the R3327-AT and FaDu rat tumor models. International journal of radiation oncology, biology, physics 2005;61:1493-502.

[49] Hansen AE, Kristensen AT, Jorgensen JT, McEvoy FJ, Busk M, van der Kogel AJ, et al. (64)Cu-ATSM and (18)FDG PET uptake and (64)Cu-ATSM autoradiography in spontaneous canine tumors: comparison with pimonidazole hypoxia immunohistochemistry. Radiat Oncol 2012;7:89.

[50] Carlin S, Zhang H, Reese M, Ramos NN, Chen Q, and Ricketts SA. A comparison of the imaging characteristics and microregional distribution of 4 hypoxia PET tracers. Journal of nuclear medicine : official publication, Society of Nuclear Medicine 2014;55:515-21.

[51] Yuan H, Schroeder T, Bowsher JE, Hedlund LW, Wong T, and Dewhirst MW. Intertumoral differences in hypoxia selectivity of the PET imaging agent 64Cu(II)-diacetyl-bis(N4-methylthiosemicarbazone). Journal of nuclear medicine : official publication, Society of Nuclear Medicine 2006;47:989-98.

[52] Valtorta S, Belloli S, Sanvito F, Masiello V, Di Grigoli G, Monterisi C, et al. Comparison of 18F-fluoroazomycinarabinofuranoside and 64Cu-diacetyl-bis(N4-methylthiosemicarbazone) in preclinical models of cancer. Journal of nuclear medicine : official publication, Society of Nuclear Medicine 2013;54:1106-12.

[53] Li F, Jorgensen JT, Forman J, Hansen AE, and Kjaer A. 64Cu-ATSM reflects pO2 levels in human head and neck cancer xenografts but not in colorectal cancer xenografts. Journal of nuclear medicine : official publication, Society of Nuclear Medicine 2015.

[54] Furukawa T, Yuan Q, Jin ZH, Aung W, Yoshii Y, Hasegawa S, et al. A limited overlap between intratumoral distribution of 1-(5-fluoro-5-deoxy-alpha-D-arabinofuranosyl)-2-nitroimidazole and copper-diacetyl-bis[N(4)-methylthiosemicarbazone]. Oncology reports 2015;34:1379-87.

[55] Bowen SR, van der Kogel AJ, Nordsmark M, Bentzen SM, and Jeraj R. Characterization of positron emission tomography hypoxia tracer uptake and tissue oxygenation via electrochemical modeling. Nuclear medicine and biology 2011;38:771-80. [56] Lewis JS, McCarthy DW, McCarthy TJ, Fujibayashi Y, and Welch MJ. Evaluation of 64Cu-ATSM in vitro and in vivo in a hypoxic tumor model. Journal of nuclear medicine : official publication, Society of Nuclear Medicine 1999;40:177-83.

[57] Brown JM and Wilson WR. Exploiting tumour hypoxia in cancer treatment. Nature reviews. Cancer 2004;4:437-47.

[58] Colombie M, Gouard S, Frindel M, Vidal A, Cherel M, Kraeber-Bodere F, et al. Focus on the Controversial Aspects of (64)Cu-ATSM in Tumoral Hypoxia Mapping by PET Imaging. Frontiers in medicine 2015;2:58.

[59] Vavere AL and Lewis JS. Examining the relationship between CU-ATSM hypoxia selectivity and fatty acid synthase expression in human prostate cancer cell lines. Nuclear medicine and biology 2008;35:273-9.

[60] Zhang Z, Machac J, Helft G, Worthley SG, Tang C, Zaman AG, et al. Non-invasive imaging of atherosclerotic plaque macrophage in a rabbit model with F-18 FDG PET: a histopathological correlation. BMC nuclear medicine 2006;6:3.

[61] Handley MG, Medina RA, Nagel E, Blower PJ, and Southworth R. PET imaging of cardiac hypoxia: opportunities and challenges. Journal of molecular and cellular cardiology 2011;51:640-50.

[62] Carli M. FDG Imaging of Atherosclerosis: How Good is the Evidence?: Society of Nuclear Medicine and Molecular Imaging.

[63] Rudd JH, Myers KS, Bansilal S, Machac J, Pinto CA, Tong C, et al. Atherosclerosis inflammation imaging with 18F-FDG PET: carotid, iliac, and femoral uptake reproducibility, quantification methods, and recommendations. Journal of nuclear medicine : official publication, Society of Nuclear Medicine 2008;49:871-8.

[64] Gao L, Chen Q, Zhou X, and Fan L. The role of hypoxia-inducible factor 1 in atherosclerosis. J Clin Pathol 2012;65:872-6.

[65] Casteleyn C, Trachet B, Van Loo D, Devos DG, Van den Broeck W, Simoens P, et al. Validation of the murine aortic arch as a model to study human vascular diseases. J Anat 2010;216:563-71.

[66] Bends A, Burns C, Yellowman-Caye P, Rider T, Salois EM, Sutherland A, et al. Community-university Research Liaisons: Translating the Languages of Research and Culture. Pimatisiwin 2013;11:345-57. 
Table 1 Experimental cohorts

Preliminary Mouse Study $(\mathrm{N}=16)$

\begin{tabular}{|c|c|c|c|}
\hline Number of Mice & Species/Diet & Age of Imaging & Radiopharmaceuticals \\
\hline 4 & ApoE-/-, SCD & $54-62$ (day 1$)$ & ${ }^{18} \mathrm{~F}-\mathrm{FDG}$ \\
\hline 9 & ApoE-/-, SCD & $54-62$ (day 2$)$ & ${ }^{64} \mathrm{Cu}$-ATSM \\
\hline 4 & $\mathrm{C} 57 \mathrm{Bl} / 6, \mathrm{SCD}$ & 43 (day 1 ) & ${ }^{18} \mathrm{~F}-\mathrm{FDG}$ \\
\hline 7 & $\mathrm{C} 57 \mathrm{Bl} / 6, \mathrm{SCD}$ & 43 (day 2) & ${ }^{64} \mathrm{Cu}-\mathrm{ATSM}$ \\
\hline \multicolumn{4}{|c|}{ Longitudinal Mouse Study $(\mathrm{N}=18)$} \\
\hline 6 & ApoE-/-, HFD & $14,23,32,41$ & ${ }^{64} \mathrm{Cu}-\mathrm{ATSM}$ \\
\hline 6 & ApoE-/-, SCD & $14,23,32,41$ & ${ }^{64} \mathrm{Cu}$-ATSM \\
\hline 6 & $\mathrm{C} 57 \mathrm{~B} 1 / 6, \mathrm{SCD}$ & $14,23,32,41$ & ${ }^{64} \mathrm{Cu}-\mathrm{ATSM}$ \\
\hline
\end{tabular}

\section{Figure Captions:}

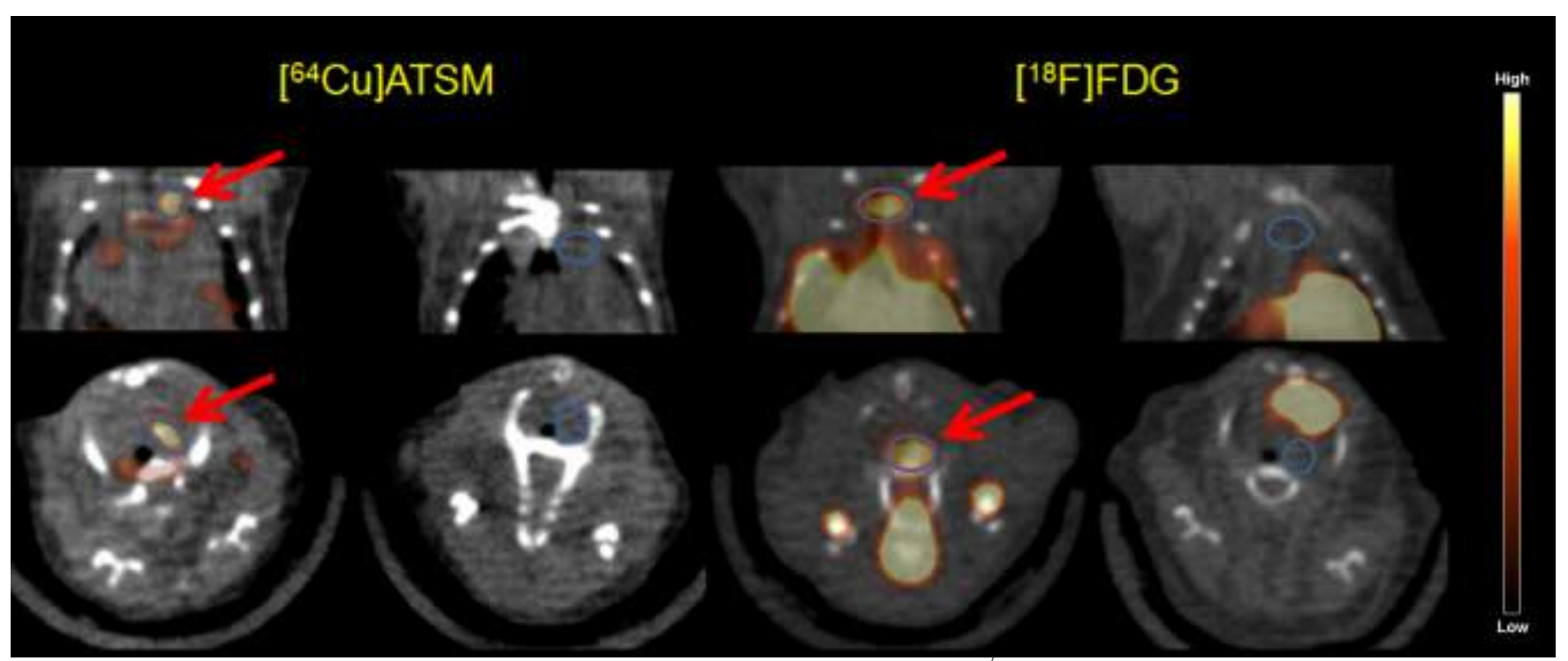

Figure 1. Representative small animal PET images from SCD ApoE ${ }^{-/-}$and wild type (control) mice. Summed images of coronal (top) and transverse (bottom) slices 7.5-30 minutes post injection (p.i.) of ${ }^{64} \mathrm{Cu}-\mathrm{ATSM}$ (left) and 40-60 minutes p.i. of ${ }^{18}$ F-FDG (right) with ROIs of aortic arch (in blue circles) drawn on each mouse. 
A

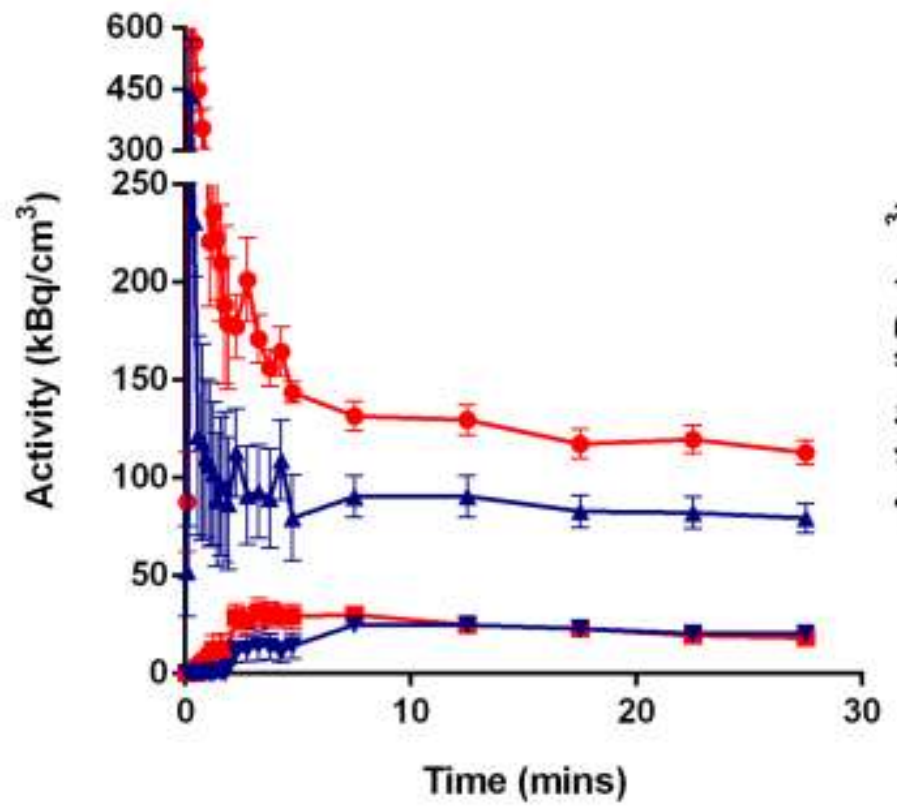

B

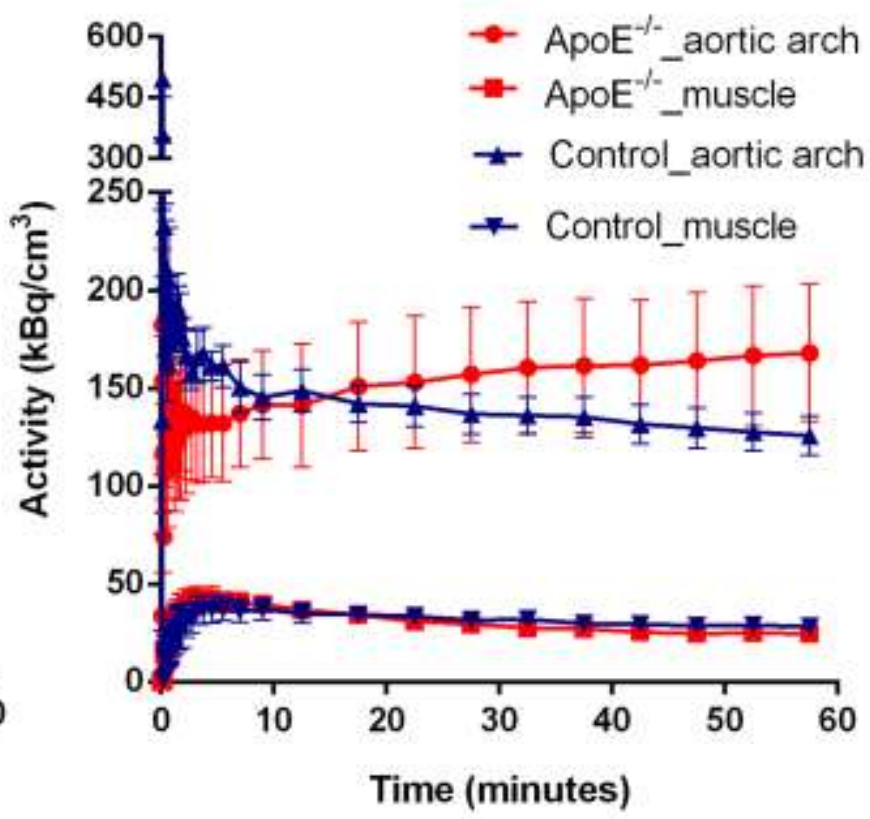

Figure 2. Time activity curves (TACs) of ${ }^{64} \mathrm{Cu}-\mathrm{ATSM}(\mathbf{A})$ and ${ }^{18} \mathrm{~F}-\mathrm{FDG}$ (B) show increased difference in aortic arch activity between the SCD ApoE ${ }^{-/-}$and wild type mice injected with ${ }^{64} \mathrm{Cu}$-ATSM in comparison to ${ }^{18} \mathrm{~F}$-FDG injection. Results are presented as mean \pm S.E.M. in the graph. The numbers of $\mathrm{ApoE}^{-/-}$and control mice were 9 and 7 for ${ }^{64} \mathrm{Cu}$-ATSM imaging, and 4 and 4 for ${ }^{18} \mathrm{~F}-\mathrm{FDG}$ imaging, respectively.

A

$\left[{ }^{64} \mathrm{Cu}\right] \mathrm{ATSM}$

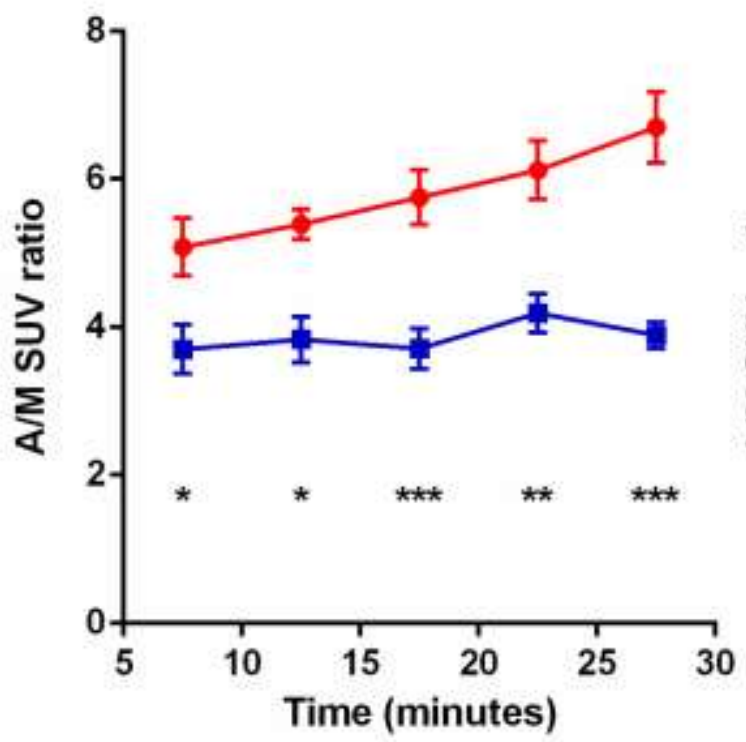

B
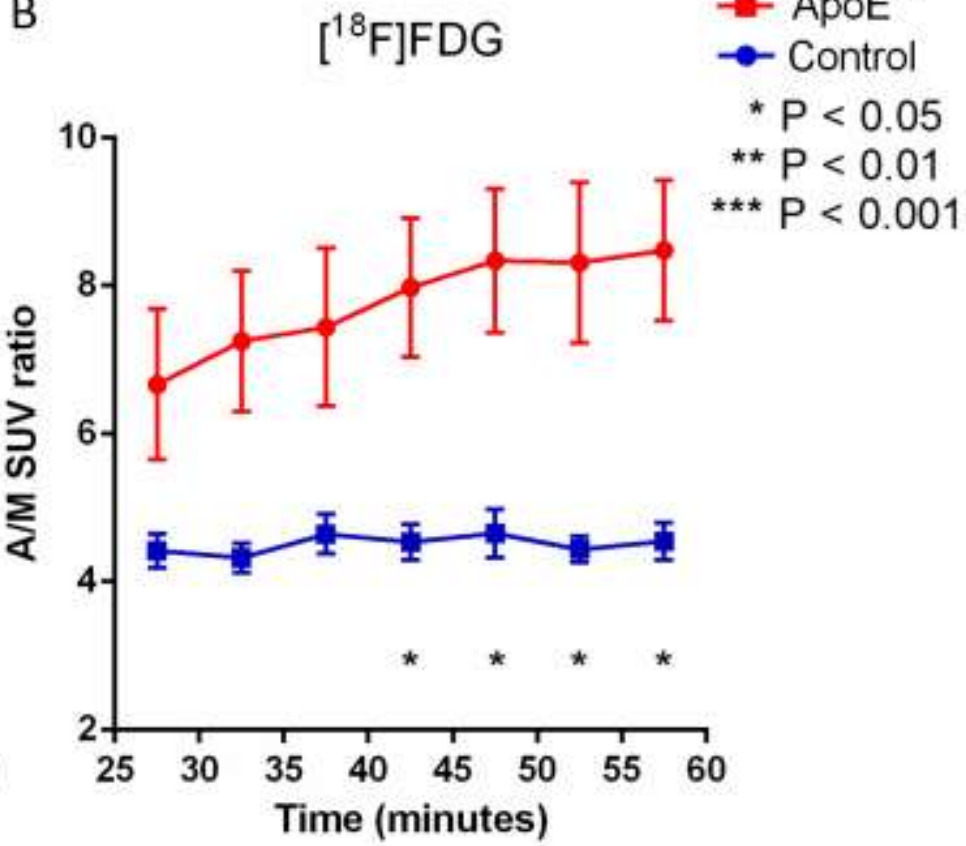

Figure 3. A/M SUV ratios observed with small animal PET imaging after injection of ${ }^{64} \mathrm{Cu}-\mathrm{ATSM}(\mathrm{A})$ and ${ }^{18} \mathrm{~F}$ FDG (B) in SCD ApoE ${ }^{-/-}$mice and control mice. ${ }^{64} \mathrm{Cu}$-ATSM injection yields significant difference in the ratios at a faster rate in comparison to ${ }^{18} \mathrm{~F}-\mathrm{FDG}$ injection, which increases over time from 7.5 minutes p.i. to the end of imaging. Results are presented as mean \pm S.E.M. in the graph. The numbers of $\mathrm{ApoE}^{-/-}$and control mice were 9 and 7 for ${ }^{64} \mathrm{Cu}$-ATSM imaging, and 4 and 4 for ${ }^{18} \mathrm{~F}-\mathrm{FDG}$ imaging, respectively. 


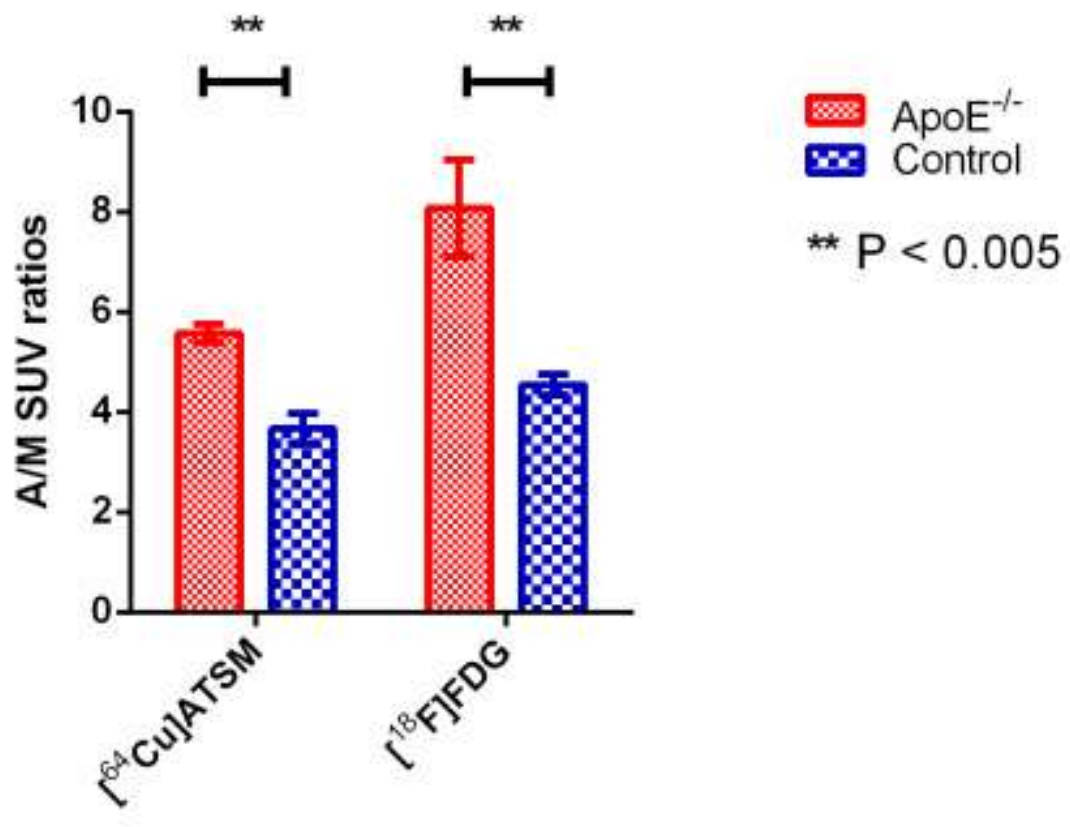

Figure 4. Comparison of A/M SUV ratios \pm S.E.M. for the same subset of SCD ApoE ${ }^{-/}$mice $(n=4)$ and control mice $(n=4) 7.5$ - 30 minutes p.i. of ${ }^{64} \mathrm{Cu}$-ATSM and 40- 60 minutes p.i. of ${ }^{18} \mathrm{~F}$-FDG. Significant differences were observed between ApoE ${ }^{-/-}$mice and control mice for both ${ }^{64} \mathrm{Cu}-\mathrm{ATSM}$ and ${ }^{18} \mathrm{~F}-\mathrm{FDG}$ imaging.
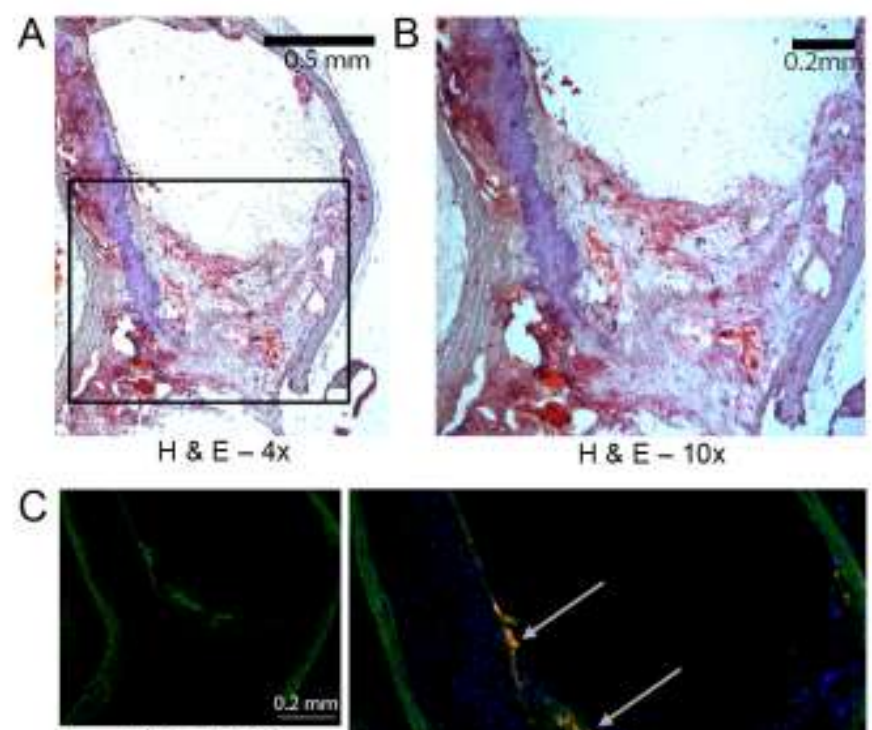

Pimo - FITC

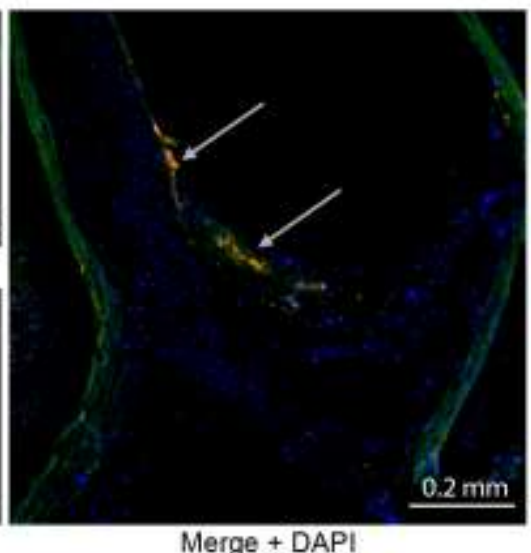

CD68 - Cy3

Merge + DAPI

Figure 5. Detection of pimodiazole adducts co-localizes with macrophages within atherosclerotic plaque of aortic arch. Aorta were harvested from 40 week old $\mathrm{ApoE}^{-/-}$mouse on western diet for 33 week that received pimodiazole 2 hours prior to sacrifice. (A) Representative image of hematoxylin and eosin stained section from aortic arch. (B) Magnification of region of interest from (A). (C) Immunofluorescence image from serial section 
of aortic arch shown in (A). PIMO is pimonidazole. Green is mAb 4.3.11.3 staining pimodiazole adducts (internal elastic lamina is autofluorescent), red is CD68 staining for macrophages, blue is DAPI nuclear stain, and yellow is the overlay of pimonidazole and CD-68. Representative of at least three animals.

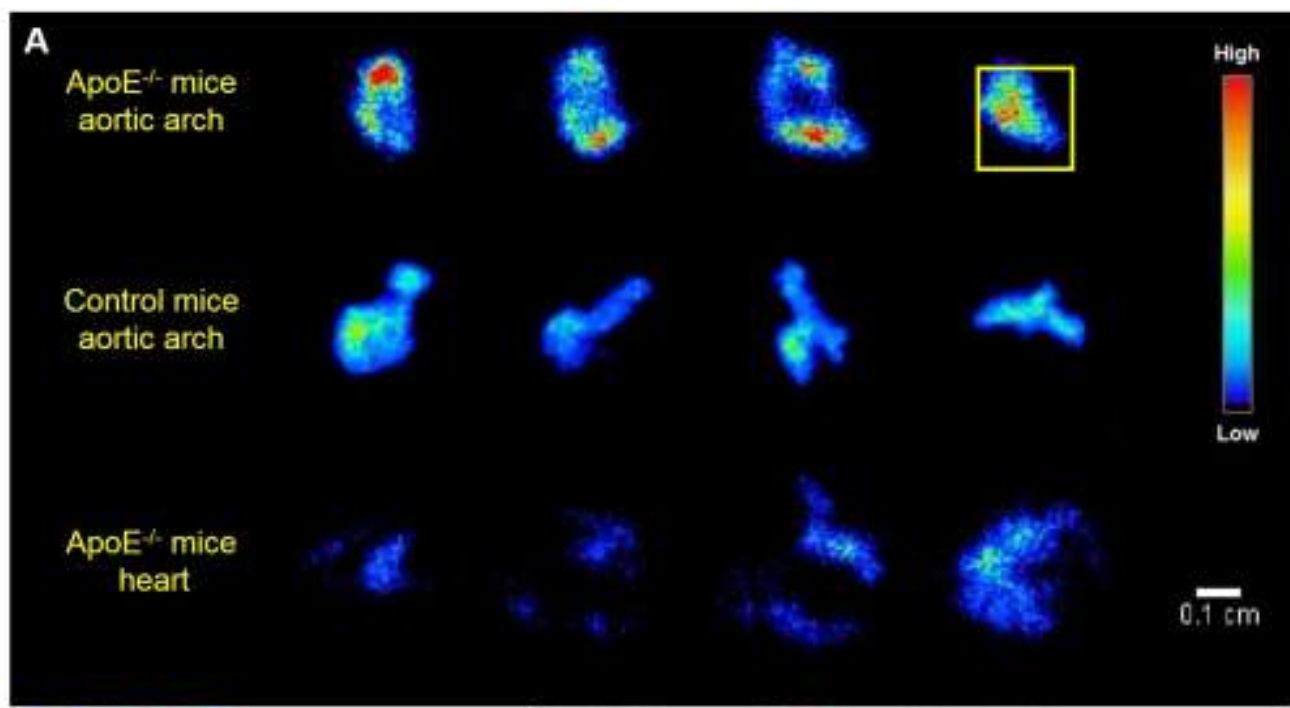

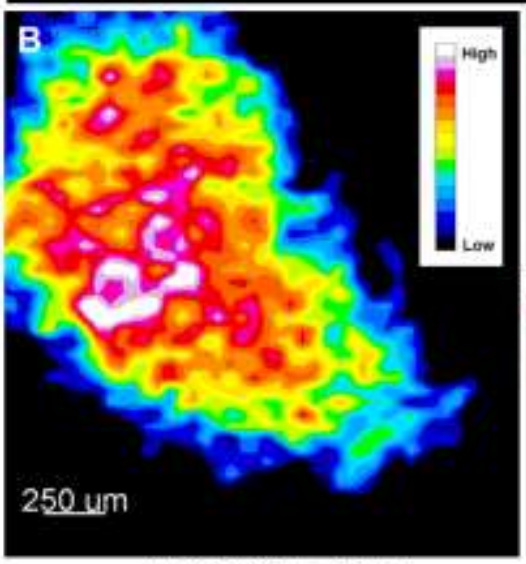

Autoradiography - scale up

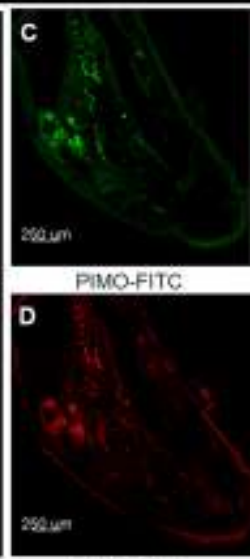

CD6B-Cy3

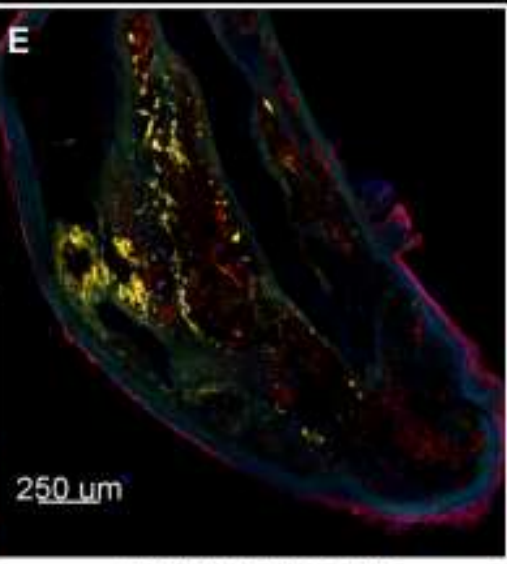

PIRO \& CDES merge + Dapi

Figure 6. (A) Representative autoradiographs obtained from transverse slices of the aortic arch in SCD ApoE ${ }^{-/-}$ mice (top) and control mice (middle) and heart in $\mathrm{SCD}^{\mathrm{ApoE}}{ }^{-/-}$mice (bottom) 30 minutes p.i. of ${ }^{64} \mathrm{Cu}-\mathrm{ATSM}$. (B) The section in the yellow square in (A) were scaled-up 11.2 times with bilinear interpolation. The bright spots in scaled-up autoradiograph were co-localized in shape to the (C) pimonidazole and (D) CD-68 strongly-positive area and their merged area. PIMO is pimonidazole. Green is $\mathrm{mAb}$ 4.3.11.3 staining pimodiazole adducts (internal elastic lamina is autofluorescent), red is CD68 staining for macrophages, blue is DAPI nuclear stain, and yellow is the overlay of pimonidazole and CD-68. 


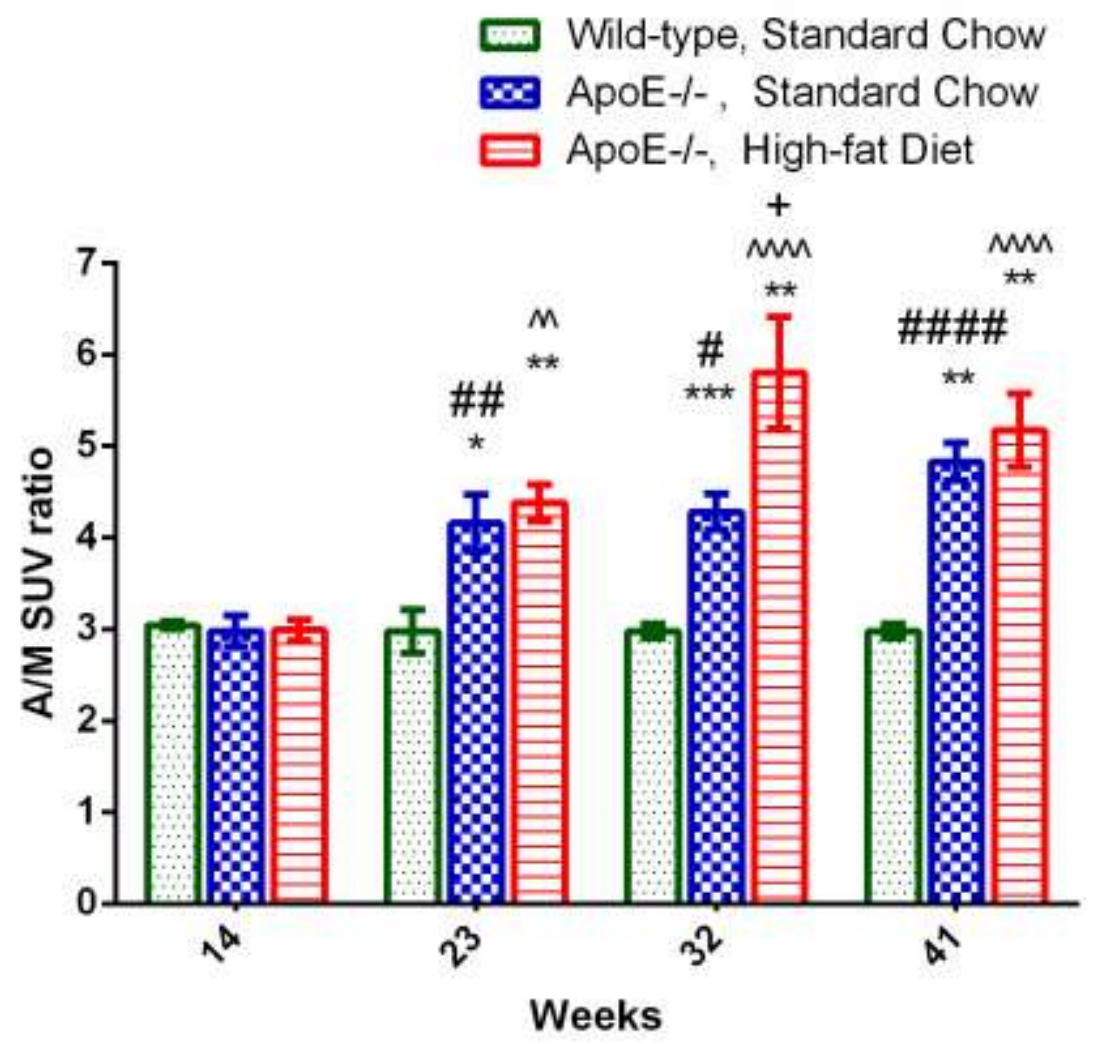

573

Figure 7. Longitudinal study of ${ }^{64} \mathrm{Cu}$-ATSM uptake in $\mathrm{ApoE}^{-/-}$mice at the same age fed either with SCD or HFD. ${ }^{64} \mathrm{Cu}$-ATSM uptakes were assessed by A/M SUV ratios as mean \pm S.E.M of $n=6 .{ }^{*} \mathrm{p}<0.01,{ }^{* * *} \mathrm{p}<0.001$, and ${ }^{* * * *} \mathrm{p}$ $<0.001$ are groups vs. 14 weeks groups. ${ }^{\#}$ p $<0.05,{ }^{\# \#}$ p $<0.01$ and ${ }^{\# \# \#}$ p $<0.0001$ are SCD ApoE ${ }^{-/-}$groups vs. SCD wild-type groups at the same age. ${ }^{\wedge} \mathrm{p}<0.01$ and ${ }^{\wedge \wedge \wedge} \mathrm{p}<0.0001$ are HFD ApoE ${ }^{-/-}$groups vs. SCD wild-type groups

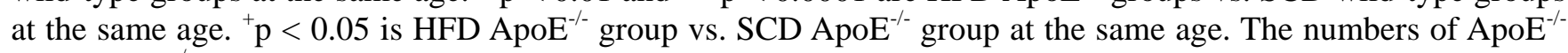
$\mathrm{HFD}, \mathrm{ApoE}^{-1-} \mathrm{SCD}$ and wild-type SCD mice were all 6. 